\title{
PRÁTICAS ESCOLARES E DESEMPENHO DOS ALUNOS: USO DAS ABORDAGENS QUANTITATIVA E QUALITATIVA
}

\author{
Alexandre Pereira Salgado Junior ${ }^{1}$ \\ Juliana Chiaretti Novi ${ }^{1}$ \\ Jonas Ferreira ${ }^{1}$
}

\begin{abstract}
RESUMO: $\mathrm{O}$ objetivo do artigo foi inter-relacionar as práticas administrativas e pedagógicas identificadas em escolas municipais do ensino fundamental que possam contribuir para o desempenho dos alunos na Prova Brasil. Para tanto, foi aplicada uma metodologia na qual são utilizadas as abordagens qualitativa e quantitativa de forma integrada e colaborativa para se estudar a eficiência escolar. Primeiramente, é aplicada a Análise Envoltória de Dados, que, por seu caráter quantitativo, classifica as escolas em eficientes e ineficientes em relaçáo ao grupo estudado. $\mathrm{Na}$ segunda etapa, qualitativa, são realizados estudos de múltiplos casos nessas escolas, visando compreender seus processos internos. Espera-se, com os resultados, poder contribuir para o alinhamento das práticas que visem auxiliar no desempenho dos alunos, na gestáo escolar e, sobretudo, proporcionar melhorias na qualidade da educação.
\end{abstract}

Palavras-chave: Práticas administrativas e pedagógicas. Ensino fundamental. Prova Brasil. Desempenho de alunos. Eficiência em educação.

\section{SCHOOL PRACTICES AND STUDENT PERFORMANCE: USE OF QUANTITATIVE AND QUALITATIVE APPROACHES}

ABSTRACT: The aim of this paper was to interrelate the administrative and pedagogical practices identified in municipal elementary schools that can contribute to student performance in Prova Brasil. To that end, it was applied a methodology in which the qualitative and quantitative approaches in an integrated and collaborative way to study the school efficiency are used. First, it is applied the Data Envelopment Analysis, which, in its quantitative character, ranks schools in efficient and inefficient compared to the study group. In the second stage, qualitative, multiple case studies are conducted in these schools, to understand its internal processes. It is expected, with the results, can contribute to the alignment of practices aiming at assisting in student performance, school management and, above all, provide improvements in the quality of education.

Keywords: Financial and pedagogical practices. Elementary education. Prova Brasil. Performance of students. Efficiency in education.

\footnotetext{
${ }^{1}$ Universidade de São Paulo, Faculdade de Economia, Administração e Contabilidade de Ribeirão Preto, Departamento de Administração - Ribeirão Preto (SP), Brasil. E-mails: asalgado@usp.br, juliananovi@fearp.usp.br, jonasferreira@usp.br DOI: 10.1590/ES0101-73302016129370
} 


\section{PRATIQUES SCOLAIRES ET ACCOMPLISSEMENT DES ÉLÈVES: UTILISATION DES APPROCHES QUANTITATIVES ET QUALITATIVES}

RÉSUMÉ: Le but de cet article est de mettre en relation les pratiques administratives et pédagogiques identifiées dans des écoles municipales de l'enseignement primaire qui puissent contribuer à la performance des élèves à la Prova Brasil (Examen Brésil). À cette fin, une méthode qualitative et quantitative de façon intégrée et collaborative a été appliquée, afin d'étudier l'efficacité scolaire. Tout d'abord, l'Analyse d'Enveloppement de Données est appliquée, qui, compte tenu de son caractère quantitatif, classe les écoles en tant qu'efficaces et inefficaces par rapport au groupe étudié. Dans la deuxième étape, qualitative, des études de plusieurs cas sont réalisées dans ces écoles, afin de comprendre leurs processus internes. Avec les résultats, on espère être en mesure de contribuer à l'alignement des pratiques qui visent à aider à la performance des élèves dans la gestion scolaire et surtout, apporter des améliorations dans la qualité de l'éducation.

Mots-clés: Pratiques administratives et pédagogiques. Enseignement primaire. Prova Brasil (Examen Brésil). Accomplissement des élèves. Efficacité dans l'éducation.

\section{Introdução}

A

educação é tema relevante nas esferas socioeconômica e política, pois sua contribuição é ampliar a formação de indivíduos que, pela aquisição do conhecimento, poderão reduzir desigualdades presentes no sistema dual (RESENDE; WYLLIE, 2006; AKKARI, 2001; CUNHA et al., 2009). Historicamente, a educação no Brasil teve uma importância secundária e, apesar de o planejamento educacional continuar sendo revisto, ela ainda apresenta as características de manter o status quo para aqueles que frequentam escolas (BELLO, 2001).

Por impactar no crescimento e desenvolvimento dos países, é importante saber que a qualidade, e não a quantidade, da educação é um fator relevante (BARRO; LEE, 2010; ANDRADE, 2011). Dados divulgados pelo Instituto Nacional de Estudos e Pesquisas Educacionais Anísio Teixeira - Inep (2013) corroboram com a representatividade do ensino fundamental ao demonstrar que, em 2012, ele continha 29,7 milhões dos 50,5 milhões de alunos matriculados na educação básica, sendo $68,2 \%$ nas redes municipais. No entanto, o aumento ao acesso à educaçáo não foi acompanhado por melhorias em sua qualidade, principalmente, àquelas oferecidas aos alunos da rede pública municipal (OLIVEIRA, 2007). 
Ao discorrer sobre o avanço da educação no Brasil, cuja principal conquista foi a universalização do ensino fundamental, Savian, Bezerra e Melo (2012) destacam que o objetivo dessa etapa, na educação básica, é promover a formação do cidadão. Resultados de avaliações internacionais mostram que há necessidade de melhorias no país, como apontam os relatórios do Fórum Econômico Mundial (BILBAO-OSORIO; DUTTA; LAVIN, 2013; ECONOMIST INTELLIGENCE UNIT, 2012), tornando evidente a necessidade de avanços na busca por uma educação de maior qualidade.

Dentre as ferramentas que podem contribuir para isso, estão os testes de avaliação em larga escala, que, apesar do questionamento existente sobre o seu verdadeiro impacto na qualidade da educação (OLIVEIRA; ARAUJO, 2005; CURY, 2010), ainda constituem uma forma de se avaliar o desempenho dos alunos no Brasil (FERNANDES; GREMAUD, 2009).

Os resultados dos testes padronizados funcionam como um termômetro da educação básica, mostrando o nível da qualidade do ensino oferecido no país (HANUSHEK, 2005). Sáo utilizados para ampliar a gama de informaçóes e subsidiar a implementação de políticas públicas educacionais (KUSIAK, 2012) que, quase sempre, esbarram na limitação dos recursos destinados às escolas públicas brasileiras (ZOGHBI et al., 2009).

"Diante deste cenário, pesquisadores brasileiros intensificam a busca pelos fatores que constituem escolas de qualidade e que influenciam no ensino" (TEIXEIRA, 2009, p. 232). No entanto, em sua maioria, os estudos na área educacional enfrentam algumas divergências metodológicas (LÜCK, 2009; ALVES; SOARES, 2013; INEP, 2013; PINTO, 2013; DOURADO; SANTOS; OLIVEIRA, 2007), com destaque para a forma de abordagem utilizada: quantitativa ou qualitativa (MEC/BID, 2010; MEC/UNICEF, 2006, 2008; UNESCO, 2004; ALVES; SOARES, 2013). Segundo Brooke e Soares (2008), a pesquisa pode estar comprometida, pois há o risco de se escolher escolas que recebem os "melhores" alunos, por exemplo, e não aquelas que mais podem contribuir para o desempenho deles.

Para Medeiros et al. (2014, p. 116), "existem diversas variáveis e dimensôes que interferem no cotidiano escolar e, por conseguinte, no aprendizado dos alunos. Devido aos objetivos da escola, à natureza de suas atividades e aos recursos utilizados em seu processo, ela pode ser considerada uma organizaçáo complexa”. Para Vergara (2005), saber os objetivos e o propósito dessa "organizaçâo" pode incrementar o comprometimento das pessoas em relação à busca de informações que poderiam consistir, por exemplo, em melhores práticas e educação para os cidadãos.

E é nesse contexto que o objetivo desta pesquisa consistiu em inter-relacionar práticas administrativas e pedagógicas identificadas em escolas municipais do ensino fundamental que podem contribuir para o desempenho dos alunos na Prova Brasil. Para tanto, foi aplicada a abordagem metodológica quali-quantitativa 
proposta por Salgado Junior e Novi (2014), que não utiliza abordagens isoladas, mas sim formas integradas e colaborativas para se estudar a eficiência escolar.

A escolha e seleção das escolas estudadas é a Análise Envoltória de Dados (DEA), que as classifica como eficientes e ineficientes, ou seja, em "alto" e "baixo" desempenho de seus alunos, com base em variáveis input-output previamente estabelecidas. Posteriormente, são realizados estudos de múltiplos casos nessas escolas, visando compreender seus processos internos.

Os dados quantitativos e os qualitativos produzem descriçóes da realidade que são igualmente ricas, mas que se diferenciam pelo grau de proximidade, "os estudos de caso nessa linha de pesquisa ainda estáo bastante restritos aos países desenvolvidos. No Brasil, é recente o esforço de realizar pesquisas desse tipo" (GAME, 2002, p. 13). A investigaçáo qualitativa tenta preencher os "espaços vazios" deixados pelos modelos estatísticos, procurando compreender como as açóes individuais são socialmente condicionadas, mas sem figurar uma abordagem psicológica, conforme sugerem os estudos de Lareau (1989).

Por fim, esta pesquisa teve o apoio da Coordenação de Aperfeiçoamento de Pessoal de Nível Superior (CAPES) em projeto contemplado pelo Programa Observatório da Educação da Capes (OBEDUC) e também da Fundação de Amparo à Pesquisa do Estado de São Paulo (FAPESP).

\section{Aspectos metodológicos}

A Figura 1 sintetiza as duas etapas da metodologia proposta por Salgado Junior e Novi $(2014 ; 2015)$. Na primeira etapa, caracterizada como quantitativa, foram consideradas como Unidades Tomadoras de Decisão (Decision Making Units - DMUs) as 10.527 escolas públicas municipais do ensino fundamental do Brasil. O objetivo dessa primeira fase foi identificar, por meio da aplicaçáo da técnica DEA, as escolas eficientes em transformar investimento anual por aluno, considerado como input nesta pesquisa, em desempenho na nota padronizada na Prova Brasil, considerado como output. Na segunda fase, caracterizada como qualitativa, são realizados estudos de caso nessas escolas, e o instrumento de pesquisa utilizado na condução das entrevistas em profundidade com os secretários municipais de educação, diretores de escolas, professores, pais e alunos foi elaborado com base no trabalho de Salgado Junior e Novi (2015).

\section{Primeira etapa: quantitativa}

Foram utilizados dados financeiros de investimento em educação fornecidos pela base de dados Finanças do Brasil (FINBRA) da Secretaria do Tesouro Nacional (STN), que disponibiliza o acesso às informaçóes sobre despesas e receitas 


\section{Figura 1}

Resumo da metodologia proposta por Salgado Junior e Novi (2014).

\section{Primeira Fase - Qualitativa}

Aplicação da DEA: identificação das

DMUs eficientes e ineficientes em

transformar inputs em outputs.

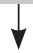

Inputs: investimento por aluno, em 2011.

Outputs: desempenho dos alunos na

Prova Brasil, em 2011.

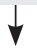

DMUs: escolas públicas municipais do ensino fundamental brasileiras.

\section{Segunda fase - Quantitativa}

Definição da amostra: escolas consideradas ineficientes com fatores predefinidos similares às eficientes.

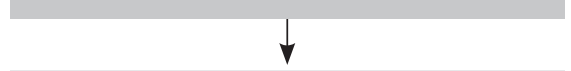

Realização de estudo de múltiplos casos nessas escolas, utilizando roteiro de entrevistas semiestruturado, focando as práticas administrativas e pedagógicas.

Comparar a frequência das práticas identificadas por meio de quadros e definir limites para diferenças significativas entre os grupos estudados.

DEA: Análise Envoltória de Dados; DMU: Unidades Tomadoras de Decisäo.

de cada município brasileiro. De acordo com Orair et al. (2011), o FINBRA é a fonte tradicionalmente mais utilizada nos estudos sobre finanças públicas municipais brasileiras. Nele tem-se acesso ao volume investido pelo município em educação fundamental anualmente. Segundo a Fundaçáo Instituto de Pesquisas Econômicas (FIPE, 2007), o FINBRA é a base de dados mais completa disponível sobre finanças públicas municipais e estaduais. Desse modo, representa a principal fonte de pesquisa por disponibilizar informaçóes sobre execução orçamentária (receita e despesa) e de balanço patrimonial (ativo e passivo) (ARAÚJO, 2012). O acesso a essas informações possibilita a construção de inúmeros indicadores para avaliação da educação municipal e estadual (FERRAZ; POLENA; QUIRINO, 2013). Ainda de acordo esses pesquisadores, por se tratar de uma base de dados autodeclarável, o FINBRA apresenta algumas limitaçóes que envolvem a inconsistência de dados, mas, mesmo com suas limitaçóes, ainda se destaca como a principal fonte de pesquisa no que se refere a informaçóes municipais, por permitir a consulta dos dados de forma agregada (municipal e estadual) em uma única planilha.

Já o Inep disponibiliza o número de alunos do ensino fundamental em escolas municipais por município, além dos dados referentes às notas médias padronizadas da Prova Brasil, em 2011, de escolas municipais brasileiras do ensino fundamental II. Assim, mediante essas informaçóes, foi possível calcular o investimento por aluno da rede municipal de cada município. 
Sobre o desempenho dos alunos do segundo ciclo na Prova Brasil (Fundamental II - $6^{\circ}$ a $9^{\circ}$ ano), no ano de 2011 , foram utilizadas informaçóes disponibilizadas pelo Inep (Censo Escolar e Prova Brasil). Essas são as duas variáveis fundamentais para o cálculo e a identificação das escolas eficientes pela técnica DEA. Por meio do desenvolvimento dessa base de dados, em que estão disponíveis as informaçóes sobre o investimento financeiro por escola pública municipal, o número de alunos por escola e o desempenho médio por escola pública municipal na Prova Brasil, tornou-se possível a identificação das escolas eficientes por intermédio dessa técnica.

De acordo com Cooper, Seiford e Tone (2007), a DEA é uma técnica utilizada para avaliar o desempenho de um conjunto de unidades que são chamadas de DMUs ou unidades tomadoras de decisão, que convertem múltiplos insumos (inputs) em múltiplos produtos (outputs). Neste estudo, utilizando o ano-base de 2011, o input considerado foi o investimento anual por aluno, e o output foi a nota padronizada da Prova Brasil.

Com o desenvolvimento dessa base de dados, que relaciona o recurso financeiro disponível por escola municipal, o número de alunos por escola e a nota da escola na Prova Brasil, foi possível o desenvolvimento das seguintes informaçóes: input do sistema (investimento anual por aluno, em 2011, das 10.157 escolas municipais do ensino fundamental consideradas no estudo) e output do sistema (nota padronizada da Prova Brasil, em 2011, das 10.157 escolas municipais do ensino fundamental consideradas no estudo). No caso da aplicação do método DEA, as variáveis utilizadas com suas respectivas justificativas são identificadas no Quadro 1.

\section{Quadro 1}

Variáveis da técnica de Análise Envoltória de Dados utilizadas.

\begin{tabular}{|l|c|c|}
\hline Descriçáo & Variável & Justificativa \\
\hline Input & $\begin{array}{c}\text { Nota padronizada } \\
\text { média dos alunos na } \\
\text { Prova Brasil em 2011. }\end{array}$ & $\begin{array}{c}\text { É um exame padronizado, utilizado em escolas } \\
\text { municipais do ensino fundamental de todo o país. }\end{array}$ \\
\hline Output & $\begin{array}{c}\text { Investimento anual } \\
\text { por aluno no ensino } \\
\text { fundamental público } \\
\text { municipal. }\end{array}$ & $\begin{array}{c}\text { Escolhidas em função de o investimento por aluno poder } \\
\text { ser calculado pela razáo do investimento anual do ensino } \\
\text { fundamental pelo município, fornecido pelo FINBRA, } \\
\text { pelo número de alunos do ensino fundamental no } \\
\text { município, fornecido pelo MEC. }\end{array}$ \\
\hline DMUs & $\begin{array}{c}\text { Escolas públicas } \\
\text { municipais do ensino } \\
\text { fundamental de todo o } \\
\text { Brasil. }\end{array}$ & Maior abrangência. \\
\hline
\end{tabular}

DMU: Unidades Tomadoras de Decisão.

A técnica DEA busca calcular a eficiência a partir da construção de uma fronteira de eficiência com o uso de técnicas de programação linear, com o objetivo de encontrar o conjunto de pesos para cada DMU que maximize o seu score 
de eficiência (variando de 0 a 1). Assim, cada DMU é comparada à sua projeção na fronteira eficiente, gerando um score de eficiência, o qual pode ser comparado a outras DMUs. Com isso, tem-se uma eficiência relativa, ou seja, é eficiente em relação ao grupo (SARAFADIS, 2002).

O cálculo da fronteira de eficiência, na qual se localizam as escolas eficientes, proporciona que elas sejam consideradas benchmark, ou seja, são tidas como referência. Com isso, foi possível identificar para o ano de 2011, em um universo das 10.157 escolas do Brasil, 7 escolas eficientes localizadas nessa fronteira. Dessa forma, destaca-se que todas as outras escolas que estão localizadas sob a fronteira de eficiência são consideradas ineficientes.

Para analisar as 10 escolas consideradas eficientes e ineficientes foi gerada a Tabela 1. Nela, as escolas A a G são caracterizadas como eficientes, e as escolas $\mathrm{H}$ a J são caracterizadas como ineficientes, selecionadas e escolhidas com score DEA abaixo de 0,6.

\section{Tabela 1}

Caracterização das escolas eficientes e ineficientes geradas pela técnica de Análise Envoltória de Dados.

\begin{tabular}{|c|c|c|c|c|c|c|c|}
\hline 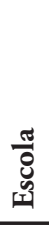 & 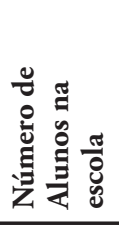 & 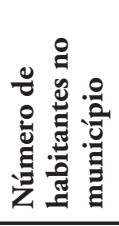 & 울 & 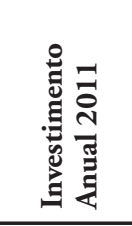 & 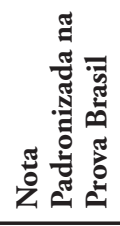 & 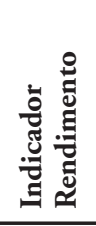 & 贫 \\
\hline A & 208 & 9.368 & SP & $\mathrm{R} \$ 3.733$ & 5 & 1 & 5 \\
\hline B & 234 & 24.699 & $\mathrm{RJ}$ & $\mathrm{R} \$ 5.810$ & 7 & 1 & 7 \\
\hline $\mathrm{C}$ & 596 & 5.802 & MG & $\mathrm{R} \$ 4.367$ & 6 & 1 & 5 \\
\hline $\mathrm{D}$ & 302 & 6.066 & $\mathrm{RS}$ & $\mathrm{R} \$ 4.604$ & 6 & 1 & 5 \\
\hline $\mathrm{E}$ & 297 & 6.873 & $\mathrm{RS}$ & $\mathrm{R} \$ 3.373$ & 5 & 1 & 5 \\
\hline $\mathrm{F}$ & 259 & 5.473 & $\mathrm{RS}$ & $R \$ 3.662$ & 5 & 1 & 5 \\
\hline $\mathrm{G}$ & 315 & 6.574 & $\mathrm{RS}$ & $\mathrm{R} \$ 4.405$ & 6 & 1 & 6 \\
\hline $\mathrm{H}$ & 370 & 15.731 & SP & $\mathrm{R} \$ 5.031$ & 4 & 1 & 3 \\
\hline $\mathrm{I}$ & 489 & 13.728 & $\mathrm{SP}$ & $\mathrm{R} \$ 4.321$ & 3 & 1 & 3 \\
\hline $\mathrm{J}$ & 205 & 19.364 & RS & $\mathrm{R} \$ 5.680$ & 4 & 1 & 3 \\
\hline
\end{tabular}

IDEB: Índice de Desenvolvimento da Educação Básica.

A seleção das escolas ineficientes foi realizada no intuito de identificar aquelas com os fatores similares aos das escolas eficientes, como investimento por aluno, nível socioeconômico (NSE), tamanho e localização. Os NSE das escolas consideradas ineficientes e eficientes neste estudo são similares (Quadro 2), conforme a classificação de Alves e Soares (2009). Com isso, entre as escolas con- 


\section{Quadro 2}

Nível socioeconômico das escolas consideradas eficientes e ineficientes (classificação de Alves e Soares, 2009).

\begin{tabular}{|c|c|c|c|c|c|c|c|c|c|c|c|c|c|}
\hline \multirow[b]{2}{*}{ Indicador } & \multirow{2}{*}{$\begin{array}{l}\text { Descriçáo } \\
\text { da atividade }\end{array}$} & \multicolumn{8}{|c|}{7 Escolas eficientes } & \multicolumn{4}{|c|}{3 Escolas ineficientes } \\
\hline & & \multicolumn{7}{|c|}{ Escolas } & $\mathrm{N}^{\circ}$ de & \multicolumn{3}{|c|}{ Escolas } & \multirow{2}{*}{$\begin{array}{c}\begin{array}{c}\mathbf{N}^{\circ} \text { de } \\
\text { escolas }\end{array} \\
0\end{array}$} \\
\hline \multirow{7}{*}{$\begin{array}{l}\text { 7. NSE } \\
\text { médio dos } \\
\text { alunos das } \\
\text { escolas } \\
\text { (ALVES; } \\
\text { SOARES, } \\
2009 \text { ) }\end{array}$} & Mais baixo & & & & & & & & 0 & & & & \\
\hline & Baixo & & & & & & & & 0 & & & & 0 \\
\hline & Médio-baixo & & & & & & & & 0 & & & & 0 \\
\hline & Médio & & & $\mathrm{C}$ & $\mathrm{D}$ & & $\mathrm{F}$ & & 3 & $\mathrm{H}$ & I & J & 3 \\
\hline & Médio-alto & A & $\mathrm{B}$ & & & $\mathrm{E}$ & & G & 4 & & & & 0 \\
\hline & Alto & & & & & & & & 0 & & & & 0 \\
\hline & Mais alto & & & & & & & & 0 & & & & 0 \\
\hline
\end{tabular}

Fonte: Elaborado pelos autores, com base em Alves e Soares (2009).

sideradas ineficientes, a amostra selecionada e escolhida tem NSE similares aos das escolas consideradas eficientes pela técnica DEA e score DEA inferior a 0,6.

Alves e Soares (2009) apresentam uma metodologia para medir o NSE, realizada por meio da Teoria de Resposta ao Item e utilizando como referência empírica os dados da Pesquisa Longitudinal da Geração Escolar de 2005 (GERES). $\mathrm{O}$ resultado obtido pelos pesquisadores foi uma escala hierárquica que mede o NSE a partir de uma combinação ponderada dos diferentes ajustes dos fatores escolaridade, ocupação e renda.

O impacto sobre o desempenho dos alunos pode ser benéfico quando há heterogeneidade na escola (FRANCO et al., 2007). Todavia, não se devem comparar escolas de NSE diferentes (FREITAS, 2007; ALVES; SOARES, 2013, 2007; CIRINO et al., 2002; COLEMAN et al., 1966; UNESCO, 2004; GREMAUD; FELÍCIO; BIONDI, 2007; LOCKHEED; VERSPOOR, 1991; SOARES; XAVIER, 2013).

\section{Segunda etapa: caráter qualitativo}

Nessa segunda fase, de abordagem qualitativa, foram realizados estudos de caso em profundidade nas dez escolas (sete localizadas na fronteira de eficiência e três consideradas ineficientes). Como já descrito, a eficiência é relativa, ou seja, as escolas são eficientes ou ineficientes em relação ao grupo em estudo.

Em relação aos procedimentos para a coleta de dados, o instrumento de pesquisa deste trabalho consistiu em um roteiro de entrevista semiestruturado utilizado em conjunto com análise documental em material fornecido pelos entrevistados 
e observação in loco do ambiente escolar em questão (SALGADO JUNIOR; NOVI, 2014, 2015; SALGADO JUNIOR et al., 2015). Como exemplo, livro de registro de retirada dos livros na biblioteca pelos alunos, conteúdo programático, regras de conduta, quadro de aviso de funcionários, infraestrutura, entre outros.

Salgado Junior e Novi (2014) utilizaram em seu estudo metodológico indicadores por eles propostos, com base e respaldo na literatura pesquisada sobre o tema. Realizaram, ainda, um focus group com uma diretora de escola e ex-secretária da educação, com o objetivo de confrontar as variáveis identificadas na literatura com as práticas pedagógicas e validar o seu instrumento de pesquisa. Para avaliar e analisar os resultados, a técnica de pesquisa utilizada foi a análise de conteúdo. Portanto, esses indicadores serviram de apoio para o desenvolvimento dos roteiros de entrevistas semiestruturadas utilizados na presente pesquisa.

As pessoas-chave para a entrevista em profundidade, com maior potencial de contribuição para este estudo foram: o secretário municipal da educação do município onde a escola está localizada; o diretor da escola; os professores de língua portuguesa e matemática das escolas selecionadas; os alunos, escolhidos aleatoriamente; e os pais de alunos, também escolhidos aleatoriamente. Outras formas de coleta de dados foram materiais fornecidos pelos entrevistados, além da observação do ambiente escolar.

\section{Resultados: práticas administrativas e pedagógicas identificadas}

As variáveis consideradas, neste estudo, serão as práticas administrativas e pedagógicas que podem contribuir para o desempenho dos alunos na Prova Brasil. Dessa forma, comparou-se nessas escolas a frequência com que essas práticas foram identificadas isoladamente. Posteriormente, foi definido o limite em que a frequência do grupo estudado fosse, significativamente, diferente entre as escolas eficientes e ineficientes (SALGADO JUNIOR; NOVI, 2015).

O critério para definir uma diferença significativa da influência da prática no desempenho do aluno foi quando a prática foi observada em, no máximo, uma escola ineficiente e, no mínimo, em cinco escolas eficientes. É importante destacar que as práticas que são consideradas sem diferença significativa também podem influenciar no desempenho, mas, para o grupo de escolas estudadas, o nível de diferença significativa definida na pesquisa e baseado na técnica DEA proposta, aparentemente, apresenta menor influência no desempenho dos alunos.

Os indicadores propostos e as respectivas práticas administrativas e pedagógicas que estão nos Quadros 3 e 4, respectivamente, foram os que apresen- 
taram diferença significativa nos estudos de caso (SALGADO JUNIOR; NOVI, 2015; SALGADO JUNIOR et al., 2015). Assim, foram encontrados com maior frequência em um grupo de escolas e, provavelmente, podem ter uma maior influência nos resultados de desempenho dos alunos.

\section{Quadro 3}

Práticas administrativas com diferença significativa no grupo de escolas eficientes e ineficientes, conforme aplicação metodológica quali-quantitativa.

\begin{tabular}{|c|c|}
\hline Indicadores & Descriçáo das práticas administrativas \\
\hline $\begin{array}{l}\text { Políticas da SME para motivação do } \\
\text { professor }\end{array}$ & $\begin{array}{l}\text { Incentivo financeiro (plano de carreira financeiramente } \\
\text { atrativo e/ou salários acima da média regional) }\end{array}$ \\
\hline Infraestrutura & $\begin{array}{l}\text { Transporte gratuito para alunos e pais de alunos (quando } \\
\text { convidados a comparecer à escola) }\end{array}$ \\
\hline Disciplina & Regras escolares claras e definidas \\
\hline \multirow{2}{*}{$\begin{array}{l}\text { Capacidade da SME e/ou da Direção } \\
\text { na captação de recursos financeiros }\end{array}$} & Recursos descentralizados (rifas e festividades) \\
\hline & Recursos providos da APM \\
\hline \multirow{4}{*}{ Destinação do recurso financeiro } & Programas de computador e software \\
\hline & Equipamentos para a sala de informática \\
\hline & Acervo para a biblioteca (livros, assinatura de jornais, etc) \\
\hline & Materiais didáticos diversos \\
\hline Critério para matrícula & Matrícula por escolha da família \\
\hline
\end{tabular}

SME: Secretaria Municipal de Educação; APM: Associação de Pais e Mestres.

\section{Quadro 4}

Práticas pedagógicas com diferença significativa no grupo de escolas eficientes e ineficientes, conforme aplicação metodológica quali-quantitativa.

\begin{tabular}{|l|c|}
\hline \multirow{3}{*}{ Indicadores } & Descriçáo das práticas pedagógicas \\
\hline \multirow{3}{*}{ Desempenho Prova de Português } & Frequência de leitura \\
\cline { 2 - 2 } & Baixa rotatividade de professores \\
\cline { 2 - 2 } Desempenho Prova de Matemática & Monitoramento do professor no rendimento do aluno \\
\cline { 2 - 2 } & Becuperação paralela e reforço no contraturno \\
\cline { 2 - 2 } & Monitoramento do professor no rendimento do aluno \\
\hline \multirow{2}{*}{ Participação da família } & Participação em reunião de pais \\
\hline \multirow{2}{*}{ Postura dos alunos na escola } & Recursos providos da APM \\
\cline { 2 - 2 } & Comportamento disciplinado \\
\cline { 2 - 2 } & Respeito à figura do professor, diretor e funcionários \\
\hline
\end{tabular}


Na Figura 2, o destaque está na prática pedagógica referente à destinaçâo dos recursos financeiros e à aquisição de computadores e equipamentos para a sala de informática. Isso porque essas práticas foram identificadas em todas as escolas ineficientes, portanto, apresentadas como evidência negativa, conforme o baixo desempenho de seus alunos na Prova Brasil. Na Figura 2, pode-se observar também uma inter-relação entre alguns indicadores propostos e as práticas.

\section{Figura 2}

Práticas observadas em relação ao desempenho dos alunos nas escolas estudadas.

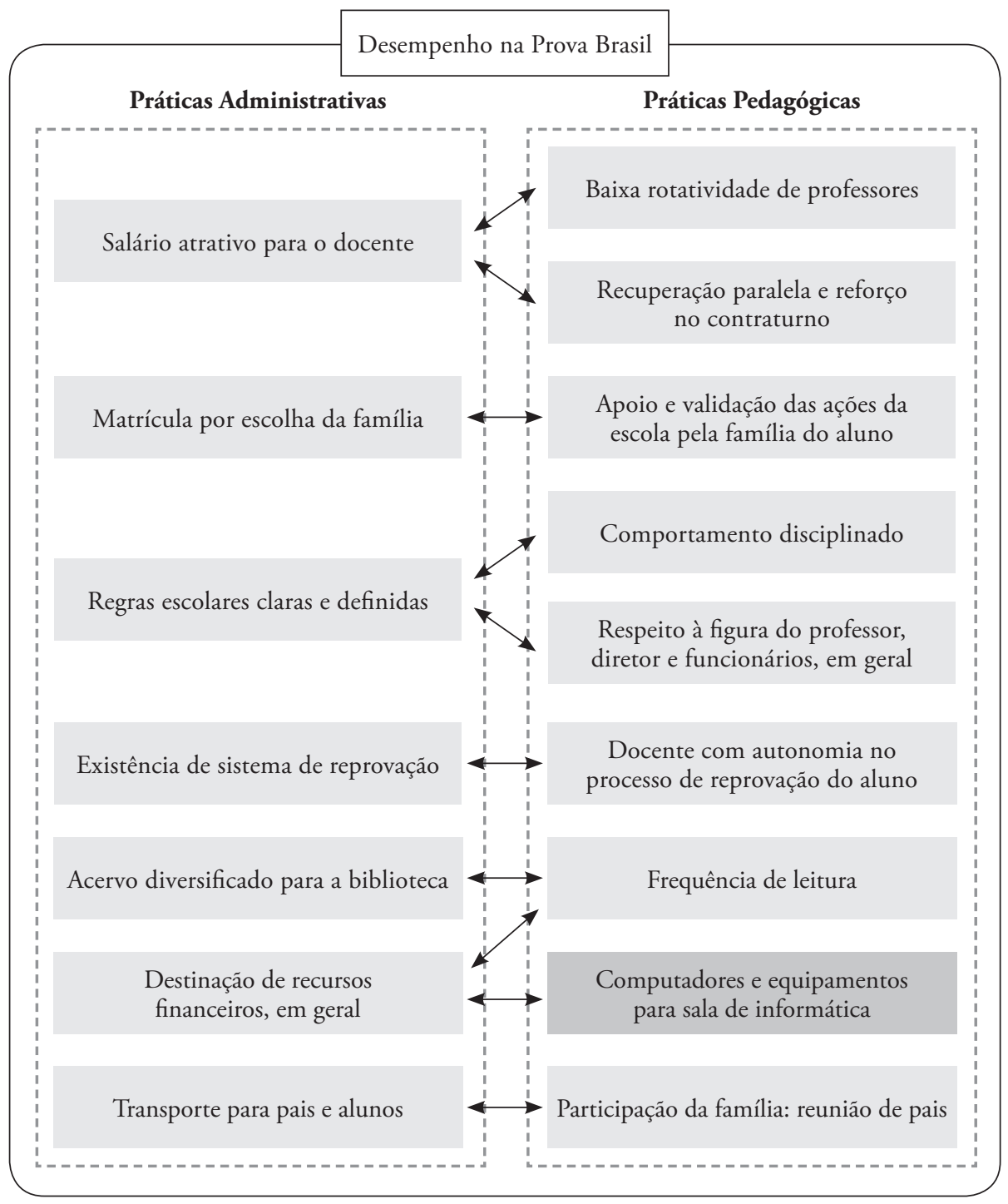




\section{Considerações sobre a inter-relação entre as práticas administrativas e pedagógicas identificadas}

Ao se estudar o grupo das sete escolas consideradas eficientes, foi possível considerar algumas inter-relaçóes relevantes entre as práticas identificadas que, provavelmente, podem ter contribuído para o desempenho dos alunos na Prova Brasil. Em relação ao grupo das três escolas consideradas ineficientes, cujos alunos apresentavam características similares às do grupo das consideradas eficientes, uma inter-relação foi apresentada com evidência negativa. Isso porque, significativamente, todas as escolas do grupo considerado ineficiente realizaram essas práticas.

Destaca-se que esses resultados corroboram com alguns estudos já realizados por outros pesquisadores, conforme Salgado Junior e Novi (2015) e Salgado Junior et al. (2015). Dessa forma, pretende-se contribuir para o alinhamento dessas práticas que visem auxiliar no desempenho dos alunos, na gestáo escolar e, sobretudo, proporcionar melhorias na qualidade da educaçấo.

Portanto, a seguir, são descritos os resultados e as consideraçóes sobre aspectos relevantes da inter-relação entre as práticas administrativas e pedagógicas identificadas e alguns indicadores.

- Prática administrativa: incentivo financeiro (salário atrativo para o docente, plano de carreira)

- Prática pedagógica: baixa rotatividade de professores, recuperação paralela e reforço no contraturno, e monitoramento docente no rendimento do aluno

Para este estudo, a rotatividade dos professores não foi considerada pela ausência de estatutários nas redes, mas sim pelo absenteísmo. Estudos que buscam identificar variáveis relacionadas à melhoria da qualidade de ensino têm, em sua maioria, afirmado que o incentivo salarial dos professores reflete no desempenho dos alunos. Esses resultados corroboram com os estudos de Gatti (2000), Gatti e Barreto (2009), MEC/Unicef (2006), MEC/BID (2010), Pinto (2013), Unesco (2004) e Setúbal (2010). Nesse sentido, nenhuma das escolas estudadas consideradas ineficientes conta com programas de incentivo salarial para os seus docentes. Essa prática administrativa foi encontrada em seis escolas consideradas eficientes.

A exceção, que é a escola "C", remunera seus professores acima da média regional, conforme os dados coletados. Destaca-se também que os gestores entrevistados acreditam ser importante a formação em gestão para exercerem suas respectivas funçôes de Secretários da Educação e/ou diretor de escola. 
A inter-relação dessas práticas identificadas também corrobora com os estudos de Soares, Alves e Oliveira (2001) e de Biondi e Felício (2007), para os quais a rotatividade de professores dificulta ou impossibilita a coesáo do grupo, pois o desempenho dos alunos é influenciado pela ausência de rotatividade dos professores ao longo do ano letivo. A inter-relaçấo dessas práticas identificadas nessas escolas foi que, conforme relato dos professores, há um sentimento de recompensar a instituição escolar e os alunos pela valorização de sua categoria naquele ambiente escolar. Conforme os relatos dos gestores, a maioria destacou a importância da formação em Gestão para os cargos de Secretário da Educação e de diretor.

No caso da escola "A", conforme pode ser identificado, os professores da rede municipal apresentam uma quantidade de faltas acima da média da escola. Uma das práticas administrativas identificadas foi que a Secretaria Municipal da Educação, em conjunto com a prefeitura, determinou uma bonificação para os que não faltassem no mês. Apesar de não ter sido observado qualquer tipo de incentivo na formação continuada de professores, os salários ofertados nessa escola estâo acima da média regional e isso acaba sendo um atrativo para os docentes. Os professores são efetivos nessa escola, desenvolvem suas próprias apostilas e têm maior envolvimento com os alunos e com esta instituição, conforme pode ser observado. Os professores podem opinar sobre quais materiais precisam ser adquiridos pela escola. A diretora relatou que atua dessa forma porque cada um sabe o que é relevante em sua área.

Já na escola "B", a SME tem como política estabelecer salários mais altos para seus professores naquela regiáo. Assim, espera-se que os melhores profissionais de outros municípios sejam atraídos para lecionar nessa escola. Verificou-se que, em sua maioria, os professores possuem graduação e pós-graduação na área de atuação, mesmo não recebendo incentivos financeiros por parte da SME para a realização desses cursos. Em relação às práticas pedagógicas nessa escola, os alunos são motivados a realizarem trabalhos em casa, orientados pelos professores. Dessa forma, o aluno tem interesse em adquirir conhecimento, pesquisar, ter contato com outras fontes de informaçóes e aprendizado, pois os alunos com bons desempenhos são reconhecidos publicamente, segundo o diretor. Foi observado que a escola elabora um ranking dos melhores alunos. Os professores desenvolvem atividades de recuperação, utilizando-se dos recursos pedagógicos tradicionais: aulas expositivas utilizando giz e lousa.

$\mathrm{Na}$ escola "C", em razão do baixo desempenho de seus alunos no Índice de Desenvolvimento da Educação Básica (IDEB) quando comparada às demais escolas do Brasil, a prefeitura do município onde ela se encontra incentivou a capacitação dos professores, auxiliando nas mensalidades para a realização de cursos de graduação e também no seu transporte até as faculdades. Em comparação a outras escolas deste estudo, esta apresentou indicador de rendimento acima da média das outras escolas eficientes, com uma evolução em seus indicadores de 
Prova Brasil. De acordo com o relato dos professores, entre 2010 e 2011, a escola desenvolveu uma política de apoio pedagógico, na qual foram oferecidas atividades específicas de recuperaçáo para os alunos com dificuldades. Tais atividades eram dirigidas e oferecidas fora da sala de aula, para acompanhamento e monitoramento dos alunos, porém no mesmo período de aula.

Identificou-se nas escolas "D" e "E" que os professores da rede municipal são mais bem remunerados que os professores da rede estadual de ensino em suas cidades. Conforme entrevistas realizadas, na escola "E", os professores não têm incentivos financeiros para, por exemplo, realizarem cursos de especialização ou pós-graduação, ou seja, não há formação continuada, mas o salário é atrativo. Ao contrário do que ocorre na escola " $F$ ", em que existe o incentivo financeiro para os professores que realizarem especializaçóes, com um plano de carreira salarial que contempla os professores com ou sem graduação e pós-graduados. Nessas escolas, são oferecidas aulas de reforço para os alunos com dificuldades, no contraturno, por outros professores.

Durante a entrevista na escola "G", foi relatado que o plano de carreira na rede estadual é melhor, porém existem algumas dificuldades que não ocorrem na rede municipal, e ainda que o salário inicial da rede municipal é maior que o da rede estadual. Juntando os dois fatores, os professores da cidade preferem a rede municipal pelo atrativo financeiro. Tal como ocorre na escola " $F$ ", os professores são incentivados financeiramente para realizar especializaçôes e também têm um plano de carreira salarial.

Não foram observadas políticas de incentivo financeiro para os professores que optem pela educação continuada nas escolas consideradas ineficientes, que incluem as "H", "I" e "J". Esta última contribui apenas com o deslocamento do professor até o estabelecimento de realização do curso. Consequentemente, conforme os relatos dos professores dessas escolas, pode-se observar que há pouquíssima motivação ou comprometimento com a instituição, existe uma falta de entrosamento entre professores, coordenadores, diretores e SME. De forma resumida, eles disseram que não há projetos pedagógicos; há dependência do material pedagógico cedido pelo governo do estado e isso é um grande problema, pois a quantidade é inadequada e não existe capacitação para que os professores utilizem tal material adequadamente. Tudo isso prejudica o trabalho uma vez que o ambiente não é propício para o desenvolvimento do trabalho pedagógico. Também foi observado que existe uma alta rotatividade no quadro de docentes nessas escolas.

- Prática administrativa: Transporte gratuito para alunos e pais de alunos

- Prática pedagógica: Participação dos pais, da família nas reuniốes das escolas 
Essas atividades incluem a participação dos pais em reunióes para acompanhamento das atividades escolares de seus filhos (reunióes bimestrais), atividades festivas (arrecadação de recursos), atividades comunitárias (feira de ciências, campeonatos, premiaçóes, etc.), conforme dados coletados nas entrevistas realizadas em todas as escolas eficientes e, inclusive, em uma ineficiente (escola J). Essa inter-relação corrobora com os estudos realizados por Alves e Soares (2007) e Ramage e Howley (2003), em que a relação entre o transporte e o desempenho escolar dos alunos é alta.

Destaque para a escola "B", cuja infraestrutura é precária, de baixo custo, com poucos recursos disponíveis e, ainda assim, a escola obteve, no ano de 2011, a maior nota na Prova Brasil dentre as 10.157 escolas consideradas nesta pesquisa. A prefeitura do município no qual se localiza essa escola oferece transporte gratuito aos seus alunos, prática também identificada nas demais escolas eficientes. Dentre as ineficientes, a escola "J" também realiza essa prática.

Pode ser observado durante as entrevistas e desempenho dos alunos, por meio de suas notas, que a família participa das atividades escolares dos seus filhos e da instituição quando recebem um estímulo, que, no caso, inclui o seu deslocamento até a escola. Em resumo, com base nos relatos obtidos, há uma participação da família no sentido de ter orgulho de os seus filhos estudarem naquela determinada escola; do esforço para que seus filhos se mantenham como bons alunos, que aprendam e adquiriam conhecimento; do respeito pela figura do diretor e do professor; pelos elogios à acessibilidade às informaçóes das escolas, por considerarem vantajoso poder ter acesso e conversar com a direção/professores, tirar dúvidas e pedir orientaçóes. Há um grande envolvimento e suporte familiar e escolar.

$\mathrm{Na}$ escola "D", por exemplo, muitos pais se oferecem para ajudar na realização de reparos na própria escola, porque, por terem a oportunidade de participar na instituição, percebem o quanto aquele ambiente é importante na educação dos alunos que a frequentam.

- Prática administrativa: Sistema disciplinar, regras escolares claras e definidas

- Prática pedagógica: comportamento disciplinado, respeito ao professor, diretor e funcionários

O background familiar no âmbito do ensino fundamental brasileiro tem estudos de Menezes-Filho (2007), Biondi e Felício (2007), Smith e Naylor (2001), e Veloso (2011), e as práticas identificadas nos estudos de casos corroboram com esses estudos. Lareau (1987) aponta que o desempenho escolar do aluno está associado à participação da sua família. Entretanto, como pode ser observado, isso não ocorre na escola J (considerada ineficiente). 
A ausência de valores pode levar à indisciplina, por isso, é importante também o apoio familiar (PIRES, 1999; PARO, 2011). Em relação à questão da importância da disciplina no estabelecimento escolar, a inter-relaçáo apresentada neste artigo corrobora também com Vasconcelos (1995), em que a maioria reconhece que sem disciplina não se podem realizar trabalhos pedagógicos significativos. Segundo Pires (1999, p. 181), desde o ensino básico até a universidade, "uma das maiores dificuldades é, sem dúvida, a indisciplina na educação. Tornouse um grande desafio, que cada vez mais tem sido alvo de preocupação das escolas, da direção, dos pais e professores”.

Em relação à reprovação do aluno, um dos efeitos negativos desse processo está na associação à falta de comprometimento por parte do aluno com a escola e a decorrente indisciplina. Alunos desinteressados não se preocupam em criar um ambiente escolar agradável para os seus colegas, pois sabem que, mesmo agindo contra o sistema escolar, ele será aprovado (CHRISTOFARI; SANTOS, 2012; PARO, 2011; JACOMINI, 2009, 2010).

Essas práticas não foram identificadas em nenhuma das escolas ineficientes. Ao contrário, foram identificadas significativamente nas escolas eficientes. Foi observada, nas entrevistas in loco com alunos, professores, diretores e funcionários, a existência de respeito mútuo entre os atores envolvidos no âmbito escolar.

Nas entrevistas, foi relatado que são disponibilizadas aos alunos ingressante nas escolas as regras de forma clara e bem expostas, estendendo-se, inclusive, aos seus pais/responsáveis. Isso porque as açóes da escola, da família e dos alunos devem estar alinhadas em conformidade com o que foi estipulado pela instituiçáo. $\mathrm{O}$ sistema disciplinar existente, como pôde ser observado, mantém o respeito recíproco entre os atores envolvidos nas escolas eficientes. Algumas das regras estão expostas nos corredores e nas salas de aula, com isso, os alunos são advertidos pelo não cumprimento delas. Existem também os “combinados” que são expostos oralmente.

O diretor da escola " $\mathrm{B}$ ” argumentou que constitui uma motivação para o bom comportamento e desempenho do aluno estar ciente das regras da escola, além da possibilidade de expulsão caso seja reprovado. Foi citado um exemplo pelo diretor: quando há a necessidade de se reunir com um professor ele expóe sua opinião, em particular, sem a participação de alunos no processo. Idem em relação aos alunos.

$\mathrm{Na}$ escola "C", em relação à postura dos próprios alunos, pode-se ressaltar que há um grande sentimento de admiração e respeito pelos professores. A escola foi muito elogiada em relação à sua estrutura física, professores, merenda, enfim, ao ambiente escolar que lhes é proporcionado.

Em entrevista realizada na escola "D", a diretora destacou que preza pela disciplina de todos os atores envolvidos no ambiente escolar, principalmente, pelo respeito dos alunos. Os valores são implícitos, não há discussões ou imposiçóes, mas os valores e posiçóes são respeitados por todos e conforme informaçóes 
fornecidas pelos entrevistados, praticamente não há problemas com questóes envolvendo indisciplina. Isso também pode ser observado nas escolas "E" e "F", inclusive com a cultura institucional de que os funcionários devem ser o exemplo.

Em relação ao sistema disciplinar nas escolas ineficientes, foi observada, na entrevista in loco e nos documentos fornecidos para a coleta de dados, a existência de muitos problemas de expulsão e advertência dos alunos. Os alunos não se sentem motivados a frequentar a escola, não se reconhecem como parte desse ambiente (não há uma identificação com o grupo de alunos da escola).

Conforme relatou uma das alunas entrevistadas na escola "I", problemas com indisciplina e conflitos entre professores e alunos são bastante frequentes, e há inclusive um professor que costuma utilizar termos inadequados com os alunos. Tais alunos não veem as figuras de autoridade da escola — professores, diretor, vice-diretor — com respeito, e os problemas com a indisciplina acabam acontecendo em várias salas. Ele parece insolúvel e incomoda a todos. Alguns professores afirmam que o processo de aprovaçáo continuada pode estar influenciando diretamente na indisciplina dos alunos, pois sabem que, mesmo desrespeitando as regras, serão aprovados nas disciplinas.

$\mathrm{Na}$ escola "J", de acordo com os professores e funcionários entrevistados, de modo geral, os alunos são muito indisciplinados, há constantes problemas de mau comportamento. Embora haja regras na escola, há grande dificuldade em cobrá-las dos alunos, e elas simplesmente não são respeitadas, sejam quais forem desde o respeito aos professores até itens do vestuário, como não usar bonés ou usar apenas os uniformes. Há também problemas com o uso de entorpecentes entre alguns alunos da escola. Muitos deles abandonam a escola e são obrigados a voltar a estudar por meio de medida judicial. Isso prejudica o ambiente porque muitos não se sentem estimulados a estudar.

- Prática administrativa: Matrícula por escolha da família

- Prática pedagógica: Apoio e validação das ações da escola

Nos estudos de caso, em todas as escolas eficientes, a família pode optar pelo estabelecimento de ensino em que os alunos estudaráo. Há o acompanhamento da família no desempenho do aluno. Nas entrevistas, observou-se que a família optou por determinada escola em decorrência da educaçáo proporcionada aos alunos. Consequentemente, existe o respeito por parte dos envolvidos pelo reconhecimento no âmbito escolar. Assim, há a inter-relaçáo com o apoio e validação das açóes da escola. Para Oliveira (2011), essas escolas são tidas como exemplo pelos pais dos alunos, os quais priorizam a matrícula de seus filhos nelas.

Nas escolas "A" e "B", há um processo seletivo para o ingresso dos alunos. Em média, 200 alunos se candidatam a esse processo seletivo todos os anos 
para as 25 vagas disponíveis na Escola “B”, e quando algum aluno é reprovado é realizada sua transferência compulsória para outra unidade escolar do município. Foi relatado que existe um grande interesse por parte dos moradores da cidade nessa escola, pois ela estimula a competitividade entre os alunos e a meritocracia.

Já na Escola "D”, não há processo seletivo para ingresso de novos alunos. Nessa escola, destacou-se o baixo indicador de rendimento entre as sete escolas consideradas eficientes pelo modelo metodológico utilizado nesta pesquisa $(0,71)$. $\mathrm{Na}$ visita in loco, ao se examinar os diários de classe e as atas dos resultados finais da escola, verificaram-se taxas de reprovação, desistência e transferência. Se o modelo proposto para seleção de escolas eficientes considerasse como output a nota do IDEB em vez da Prova Brasil, essa escola muito provavelmente não estaria entre as escolas eficientes. Dentre as eficientes, a escola "D" é que apresenta a segunda maior nota na Prova Brasil $(6,30)$, mas apresenta o menor IDEB $(4,50)$. Isso é causado pelo baixo indicador de rendimento dela. No entanto, como o indicador de rendimento não é considerado pelo modelo proposto, ela pode ser considerada eficiente.

Nas Escolas "H”, "I” e “J”, identificou-se que somente nesta última a matrícula é por escolha da família. Nas outras duas, a matrícula de alunos é feita por zoneamento.

- Prática administrativa: Capacidade da Secretaria Municipal da Educação e/ou Direçáo na captaçáo de recursos financeiros - Recursos descentralizados (rifas e festividades)

- $\quad$ Prática pedagógica: Participação familiar - reunião de pais e apoio e validação das açôes da escola; recursos providos pela Associação de Pais e Mestres

Nesse caso, pode-se observar que essas práticas foram identificadas significativamente nas escolas consideradas eficientes e em nenhuma das escolas consideradas ineficientes.

$\mathrm{Na}$ escola "A", um valor razoável de lucro é obtido pela venda dos insumos agrícolas da instituição (gado, café, milho, verduras, etc.), por meio da Associação de Pais e Mestres (APM), totalizando aproximadamente R\$ 60.000,00/ano. Essa arrecadação é reinvestida na própria escola, na qual o diretor, com a APM, tem autonomia para decidir a alocação mais relevante do recurso financeiro. Exemplos de aquisiçóes para a escola foram: geladeira, freezer, bebedouro, uniformes, etc. Com relação aos recursos descentralizados do Programa Dinheiro Direto na Escola (PDDE), foi observado nas entrevistas que, apesar de ser disponibilizada para a escola essa assistência financeira, ela não tem autonomia para investi-la da forma que achar mais importante. Ademais, o recurso do PDDE, que é cerca de $\mathrm{R} \$ 4.000,00 /$ ano, nessa escola é inferior aos recursos provenientes da APM (que totalizam aproximadamente $\mathrm{R} \$ 30.000,00 / \mathrm{ano})$. 
Na escola "B", o PDDE que a escola recebe é de cerca de R \$ 4.500,00 ao ano, dinheiro o qual é gasto apenas em materiais voltados diretamente aos alunos. Os demais materiais que a escola necessita são solicitados e atendidos pela SME, segundo afirmou o diretor. Já na escola "C", há uma verba de R\$23.000,00/ano, sendo $\mathrm{R} \$ 13.000,00$ provenientes do PDDE e $\mathrm{R} \$ 10.000,00$ arrecadados por meio de eventos, como gincanas e festas (APM). Esse recurso descentralizado é investido, normalmente, em materiais voltados para os alunos e materiais pedagógicos, pois as demais necessidades da escola são atendidas pela SME, conforme entrevista com a direção. A diretora também afirmou não sentir falta de recursos financeiros na escola, ou seja, os recursos recebidos são suficientes e bem investidos. Foi observado que a SME dessa escola tem um departamento no qual os funcionários pesquisam sobre os programas oferecidos pelos governos. Dessa forma, tentam aderir a todos os programas cabíveis e aumentam seus recursos financeiros.

A escola "D" recebe o PDDE no valor de R\$3.000,00/anual e da APM, $\mathrm{R} \$ 12.000,00 /$ anual. Segundo a diretora, o recurso descentralizado normalmente é investido em material pedagógico. A APM é atuante na escola, conforme os relatos das entrevistas. São realizados, inclusive, mutirōes para arrumar as dependências da escola (ajuda de mão de obra coletiva), assim como nas escolas "E" e "F". Esta, conforme informaçóes, recebe do PDDE cerca de R \$ 4.000,00/ano e da APM R \$ 3.500,00/ano (rifas e festas). Aquela recebe do PDDE R \$ 8.000,00/ano e da APM, R\$ 20.000,00 (rifas e festas). Na escola "G", o recurso descentralizado é de $\mathrm{R} \$ 3.000,00 /$ anual do PDDE e de R \$ 8.000,00/anual de rifas e festas (APM). Em todas elas os recursos são investidos em material pedagógico.

$\mathrm{Na}$ escola "H", a direção investe recursos descentralizados em gastos aparentemente desnecessários como, por exemplo, construção de um elevador para a cozinha. Nessa escola, foi observada a dificuldade em trazer a comunidade para participar das atividades. Um dos motivos relatados foi que, antigamente, eram realizados eventos na própria escola (Festa Junina, por exemplo), mas a SME fez com que as festividades fossem realizadas em um lugar comum. Assim, ocorreu uma desvinculação e um distanciamento entre a comunidade e a escola. Foi identificado que os pais não se interessam ou sequer têm conhecimento do que está ocorrendo no ambiente escolar.

$\mathrm{Na}$ escola "I", o diretor não soube identificar onde poderia ser investido o recurso descentralizado nem opinar sobre as necessidades da utilização desses recursos. A participação da APM é ínfima, como pode ser observado, além do desconhecimento do diretor sobre o PDDE. Já na escola "J", o valor recebido do PDDE é de R \$ 5.000,00/ano, e a APM arrecada somente R \$160,00, pois praticamente não recebe auxílio financeiro dela.

Desse modo, as formas de captação de recursos podem variar de escola para escola, mas a sua destinação também pode contribuir quando bem ou mal direcionada para o desempenho dos alunos, conforme as consideraçôes das práticas a seguir. 
- Prática administrativa: Destinação de recursos financeiros; acervo para a biblioteca (livros, jornais, etc.)

- Prática pedagógica: Frequência de leitura

Essas práticas não foram identificadas em nenhuma das escolas consideradas ineficientes. Por outro lado, foram encontradas de forma significativa nas escolas eficientes. Com isso, essas evidências corroboram com os estudos de Sacavino (2006), que afirma que o baixo desempenho se deve à falta de apoio de material pedagógico e destaca que a escola deve contar com material didático de qualidade.

Segundo Menezes-Filho (2007), é necessário gerir com eficiência os recursos disponíveis em cada escola; a má gestâo dos recursos contribui para a grande heterogeneidade existente no desempenho dos alunos. O acervo para a biblioteca e, sobretudo, sua utilização são importantes, por isso, sua inter-relação com a frequência de leitura (Figura 1). Delmanto (2009) destaca que é um dever da escola direcionar práticas para orientar e desenvolver a capacidade dos alunos em fazer uso da leitura, pois isso enriquece o processo de ensino-aprendizagem. Em muitas escolas pesquisadas no presente estudo, os alunos não acessam o acervo, pois não recebem estímulos para isso. Nos estudos de caso, pode ser observado que o controle de retirada de livros pelos alunos das escolas eficientes era relativamente superior aos das escolas ineficientes. Estas, inclusive, em sua maioria, nem dispunham de controle sobre a frequência de leitura de seus alunos ou sequer espaço físico para a biblioteca.

A importância e a relevância que a leitura desempenha na formação crítica do aluno e na sua capacidade de contextualização foram identificadas em vários estudos acerca dessa atividade. Inclusive, estudos relacionados às dificuldades encontradas por alunos na graduação por não terem adquirido o hábito da leitura nas fases iniciais de aprendizagem e que, atualmente, reflete o seu desempenho insatisfatório ao longo dos ciclos (SOUZA; SOUZA; BONFIM, 2010; DELMANTO, 2009; BORUCHOVITCH, 2001). O hábito da leitura deve ser praticado pelos alunos desde os anos iniciais, cabendo conjuntamente à escola e à família influenciar e disponibilizar meios para que esse interesse seja despertado; assim, a escrita e a interpretação dos textos podem favorecer o aprendizado (DELMANTO, 2009). Segundo Farias (2010, p. 2), "diante da evolução tecnológica, as pessoas deixaram a leitura de livros, jornais e revistas de lado, e com isso, fizeram com que os jovens ficassem cada vez mais desinteressados em praticar a leitura".

$\mathrm{Na}$ escola "A", a biblioteca é limitada no que se refere ao acervo e à infraestrutura, não existe espaço coletivo para a leitura, por isso os alunos preferem levar os livros para casa. Checando o registro de retirada de livros, chegou-se à média de locaçáo de dois livros por mês por aluno. Foi relatado que os recursos 
financeiros, provenientes das APMs, do PDDE, de rifas e festividades ou de parcerias com empresas, são destinados majoritariamente a acervo para a biblioteca (livros, assinaturas, jornais), materiais didáticos diversos (utilizados pelos professores em função de suas demandas específicas) e para equipamentos de uso geral (copiadora, vídeo, TV, máquina fotográfica).

Na Escola "C", observou-se uma boa infraestrutura, as salas são amplas e arejadas, assim como a biblioteca, que contém um acervo considerável; ainda, pode ser observado pelos livros de registro que existe um forte estímulo à leitura. A Escola conta com uma biblioteca comunitária na qual os alunos frequentemente retiram exemplares.

Na Escola "G", a instituição é antiga e insuficiente. O pátio é alugado da escola ao lado, não há espaço físico para a prática de educação física, e a biblioteca e as salas de aula são muito pequenas. Apesar disso, foi verificado pelo livro de registros da biblioteca que os alunos retiram muitos exemplares.

A Escola "H" contém uma biblioteca a qual é limitada no que se refere ao acervo e à infraestrutura. Checando o registro de retirada de livros, chegou-se à conclusão que os alunos não frequentam a biblioteca nem fazem a retirada dos livros.

- Prática administrativa: Destinação de recursos financeiros

- Prática de evidência negativa: Nenhuma prática identificada nas escolas consideradas eficientes, mas significativamente nas ineficientes: Programas de computador e software e equipamentos para a sala de informática

Seguem as consideraçóes sobre essa prática referente à destinação dos recursos financeiros e à aquisição de computadores e equipamentos para a sala de informática. Isso porque essas práticas foram identificadas em todas as escolas ineficientes, portanto, são apresentadas como evidência negativa.

$\mathrm{Na}$ escola "B", destaca-se que existe uma sala de informática muito precária na escola. No entanto, os alunos não a utilizam, pois ela se encontra fechada há três anos por falta de funcionários. A escola "C" dispóe de uma sala de informática que funciona com a biblioteca com alguns recursos investidos e foi relatado que ela muito pouco utilizada.

As escolas "D" e "F" contêm salas de informática desativadas por estarem com muitos computadores com problemas de funcionamento e pelo tamanho das salas (pequenas) para comportar os alunos. Já as escolas "E" e "G" não têm salas de informática, pois foi relatado que o espaço físico da instituição é limitado.

Dentre as escolas ineficientes, a destinação dos recursos financeiros das Escolas "H", "I" e "J", provenientes das APMs, do PDDE, de rifas e 
festividades ou de parcerias com empresas, também são destinados a equipamentos de uso geral (copiadora, vídeo, TV, máquina fotográfica). Entretanto, também foi relatado que se destinam à aquisição de equipamentos para a sala de informática, programas de computador e softwares. Dentre as consideradas ineficientes, todas contêm salas de informática que funcionam de forma precária. Os alunos as utilizam basicamente para pesquisas sem supervisão de professores, conforme relatado e observado. $\mathrm{O}$ acesso à internet não é controlado pelos funcionários ou professores. Inclusive, em algumas delas, o acesso à internet sequer funciona.

Nenhuma prática dessas foi identificada nas escolas eficientes, mas significativamente nas ineficientes. Equipamentos estão encaixotados por não haver professores que os utilizem ou "salas" disponíveis; não há acesso à internet. Recomenda-se que os estabelecimentos de ensino disponibilizem aos seus alunos uma infraestrutura adequada, proporcionando melhorias no rendimento e estimulando sua permanência no ambiente escolar, pois isso é fundamental no seu processo de aprendizagem (MEC/UNICEF, 2006).

Como pode ser observado, as atividades que culminam na aquisição de recursos para informática acabaram sendo encontradas de forma acentuada nas escolas ineficientes. Dessa forma, elas foram destacadas por não haver evidências de qualquer inter-relação com as práticas, com base nos dados coletados. Nesse sentido, as evidências corroboram com os estudos a seguir. De acordo com Kulik (2003), os recursos alocados para se adquirir esses equipamentos, em sua maioria, não contam com acesso à internet ou com profissionais aptos a implantá-los nos processos pedagógicos, inclusive, acabam diminuindo a aprendizagem na leitura dos alunos.

Corroboram também com os estudos de Dwyer et al. (2007), segundo os quais a utilizaçáo de computadores pelos alunos interfere negativamente no seu desempenho escolar. De acordo com Firpo e De Pieri (2012, P. 178), "se constatam resultados de longo prazo nulos ou negativos, indicando que crianças mais velhas, quando expostas a tecnologias de informação nas escolas, não apresentam ganhos de aprendizado".

Deve-se garantir que os recursos de informática sejam utilizados para fins pedagógicos (BIONDI; FELÍCIO, 2007; PINTO, 2013). Segundo Lopes et al. (2009, p. 6), "ferramentas tecnologicamente mais modernas e/ou sofisticadas indica uma maior fluência em tecnologias e, apesar de potencializar a aprendizagem, não garante seu uso pedagógico efetivo". Para Menezes-Filho (2007), esses resultados indicam que é preciso repensar o papel do computador no ensino, sobretudo para os alunos da rede pública, para quem o uso do computador está associado a uma piora nas suas notas ou na redução do desempenho. Nesse contexto, o presente trabalho identificou evidências negativas em relação a essas práticas. 


\section{Referências}

AKKARI, A.J. Desigualdades educativas estruturais no Brasil: entre Estado, privatização e descentralização. Educação \& Sociedade, v. 22, n. 74, 2001.

ALVES, M.T.G.; SOARES, J.F. As pesquisas sobre o efeito das escolas: contribuiçôes metodológicas para a Sociologia da Educação. Sociedade e Estado, v. 22, n. 2, p. 435-473, 2007.

Medidas de nível socioeconômico em pesquisas sociais: uma aplicação aos dados de uma pesquisa educacional. Opinião Pública, v. 15, p. 1-30, 2009.

Contexto escolar e indicadores educacionais: condiçóes desiguais para a efetivaçáo de uma política de avaliação educacional. Educação e Pesquisa, v. 39, n. 1, p. 177-194, 2013.

ANDRADE, E.C. Rankings em educação: Tipos, problemas, informaçôes e mudanças: Análise dos principais rankings oficiais brasileiros. Estudos Econômicos, v. 41, n. 2, p. 323343, 2011.

ARAÚJO, R.L.S. Desvendando o perfil dos gastos educacionais dos municípios brasileiros. Educação \& Sociedade, v. 33, n. 121, p. 1215-1233, 2012.

BARRO, R.J.; LEE, J. A new data set of educational attainment in the world, 19502010. National Bureau of Economic Research, NBER Working Paper Series, Working Paper 15902, 2010.

BELlO, J.L. de P. Educação no Brasil: a História das rupturas. Pedagogia em Foco, 2001. Disponível em: <http://bve.cibec.inep.gov.br/ac rap.asp?cat=73\&nome=História\%20 da\%20Educação >. Acesso em: 01 jul. 2015

BILBAO-OSORIO, B.; DUTTA, S.; LANVIN, B. The Global Information Technology Report 2013: Growth and Jobs in a Hyperconnected World. World Economic Forum and INSEAD, 2013.

BIONDI, R.L.; FELÍCIO, F. Atributos escolares e o desempenho dos estudantes: uma análise em painel dos dados Saeb. Brasília: Instituto Nacional de Estudos e Pesquisas Educacionais Anísio Teixeira (Inep), 2007.

BORUCHOVITCH, E. Algumas estratégias de compreensão em leitura de alunos do ensino fundamental. Psicologia Escolar e Educacional, v. 5, n. 1, 2001.

BROOKE, N.; SOARES, J.F. Pesquisa em eficácia escolar: origens e trajetórias. Belo Horizonte: Ed. UFMG, 2008.

CHRISTOFARI, A.C.; SANTOS, K.S. Políticas locais de reestruturação curricular por ciclos: avanços e desafios. Revista Brasileira de Educação, v. 17, n. 50, 2012.

CIRINO, P.T. et al. Measuring Socioeconomic Status: Reliability and Preliminary Validity for Different Approaches. Assessment, v. 9, n. 2, p. 145-155, 2002.

COLEMAN, J.S. et al. Equality of educational opportunity. Washington, DC: US, 1966. Disponível em: <http://www.icpsr.umich.edu/icpsrweb/ICPSR/studies/06389> Acesso em: 30 out. 2013. 
COOPER, W.W.; SEIFORD, L.M.; TONE, K. Data envelopment analysis: a comprehensive text with models, applications, references and DEA-solver software. New York: Springer Science, 2007.

CUNHA, J.M.; JIMENEZC, M.A., PEREZD, J.R.R.; ANDRADE, C.Y. Social segregation and academic achievement in state-run elementary schools in the municipality of Campinas, Brazil. Geoforum, v. 40, n. 5, set, p. 873-883, 2009.

CURY, C.R.J. Qualidade em Educação. Nuances, v. 17, p. 17-34, 2010.

DELMANTO, D. A leitura em sala de aula. Almanaque do Programa Escrevendo o Futuro, n. 7, 2009.

DOURADO, L.F.; SANTOS, C.A.; OLIVEIRA, J.F. A qualidade da educaçâo: conceitos e definiçóes. Série Documental (Inep), Brasilia, v. 24, n.22, p. 05-34, 2007.

DWYER, T. et al. Desvendando mitos: os computadores e o desempenho no sistema escolar. Educação \& Sociedade, v. 28, n. 101, p. 1303-1328, 2007.

ECONOMIST INTELLIGENCE UNIT. The Learning Curve: Lessons in Contry Performance in Education 2012 Report. Londres: Pearson. Disponível em: <http://thelearningcurve.pearson.com/index/index-ranking >. Acesso em: 15 nov. 2013.

FARIAS, M.P. de. Refletindo a prática de leitura no ensino superior. Revista Multidisciplinar IESC, v. 1, n. 2, 2010.

FERNANDES, R.; GREMAUD, A.P. Qualidade da Educação: avaliação, indicadores e metas. In: VELOSO, F. et al. (Orgs.). Educação básica no Brasil: construindo um país do futuro. Rio de Janeiro: Elsevier, 2009.

FERRAZ, J; POLENA, A.; QUIRINO, S.R. Finbra e Siop, o que os dados nos dizem. In: XXVI Simpósio Brasileiro de Política e Administração da educação, 2013, Recife. XXVI Simpósio Brasileiro de Política e Administração da educação, 2013.

FIRPO, S.P.; DE PIERI, R.G. Avaliando os efeitos da introdução de computadores em escolas públicas brasileiras. Revista Brasileira de Inovação, v. 11, p. 153-190, 2012.

FRANCO, C. et al. Qualidade e eqüidade em educação: reconsiderando o significado de "fatores intraescolares". Ensaio: Avaliação e Políticas Públicas em Educação, v. 15, n. 55, p. 277-298, 2007.

FREITAS, L. C. de. Eliminação adiada: o ocaso das classes populares no interior da escola e a ocultação da (má) qualidade do ensino. Educação \& Sociedade, v. 28, n. 100, p. 965-987, 2007.

FUNDAÇÃO INSTITUTO DE PESQUISA ECONÔMICA - FIPE. Qualidade do gasto público no Brasil: sugestôes para melhorar os resultados das politicas públicas, sem aumento de impostos. Instituto Brasileiro de Ética Concorrencial (ETCO) e Fundação Instituto de Pesquisa Econômica. 2007.

GATTI, B.A. Formação de professores e carreira: problemas de movimento e renovação. 2. ed. Campinas: Autores Associados, 2000.

GATTI, B.A.; BARRETO, E.S.S. Professores: aspectos de sua profissionalização, formação e valorização social. Brasília: Unesco, 2009. Relatório de Pesquisa. 
GREMAUD, A.P.; FELICIO, F.; BIONDI, R.L. Indicador de Efeito Escola: uma metodologia para a identificaçáo dos sucessos escolares a partir dos dados da Prova Brasil. Brasília: Instituto Nacional de Estudos e Pesquisas Educacionais Anísio Teixeira, 2007.

GRUPO DE AVALIAÇÃO E MEDIDAS EDUCACIONAIS - GAME. Escola Eficaz: um estudo de caso em três escolas da rede pública de ensino do Estado de Minas Gerais. Belo Horizonte, 2002, 114 p.

HANUSHEK, E. School and academic achievement. Econometrica. v. 73, n. 2, p. 417458, 2005.

INSTITUTO NACIONAL DE ESTUDOS E PESQUISAS EDUCACIONAIS ANÍSIO TEIXEIRA - INEP. Censo Escolar da Educação Básica 2012. 2013.

JACOMINI, M.A. Educar sem reprovar: desafio de uma escola para todos. Educação e Pesquisa, v. 35, n. 3, p. 557-572, 2009.

Por que a maioria dos pais e alunos defende a reprovação? Cadernos de Pesquisa, v. 40, n. $141,2010$.

KULIK, J.A. Effects of using instructional technology in elementary and secundary schools: what controlled evaluation studies say? Arlington: SRI International, 2003.

KUSIAK, S.M. Uma análise da prova Brasil com enfoque nos processos de leitura e escrita. Cadernos ANPED, v.1, p. 1-10, 2012.

LAREAU, A. Social class differences in family-school relationships: the importance of cultural capital. Sociology of education, v. 60, 1987.

Home advantage: social class and parental intervention in elementary education.

Londres: The Falmer Press, 1989.

LOCKHEED, M.E.; VERSPOOR, A.M. Improving primary education in developing countries. Ed. Associates, Oxford: Oxford University Press for the World Bank, 1991.

LOPES, R.D. et al. O uso do computador e da internet nas escolas públicas de capitais brasileiras. Laboratório de Sistemas Integráveis (LSI) do Departamento de Engenharia de Sistemas Eletrônicos da Escola Politécnica da Universidade de São Paulo. Estudos e Pesquisas Educacionais, 2009.

LÜCK, H. Dimensóes de gestão escolar e suas competências. Curitiba: Editora Positivo, 2009.

MEDEIROS, M.L.; FEROLLA, L.M.; PASSADOR, C.S.; PASSADOR, J.L. Gestão escolar: afinal, que fins estão sendo buscados? RBPAE, v. 30, n. 1, p. 115-138, 2014.

MENEZES-FILHO, N.A. Os Determinantes do Desempenho Escolar no Brasil. São Paulo: Instituto Futuro Brasil, Ibmec - SP e FEA-USP, 2007.

MINISTÉRIO DA EDUCAÇÃO - MEC; BANCO INTERAMERICANO DE DESENVOLVIMENTO - BID. Melhores práticas em escolas de ensino médio no Brasil. Brasília: Instituto Nacional de Estudos e Pesquisas Educacionais Anísio Teixeira, 2010.

MINISTÉRIO DA EDUCAÇÃO - MEC; FUNDO DAS NAÇÓES UNIDAS PARA A INFÂNCIA - UNICEF. Aprova Brasil: O direito de aprender. Estudos de boas práticas de educação pública em escolas avaliadas pelo Prova Brasil: caderno de campo - orientaçóes e instrumentos de trabalho para os pesquisadores. Brasília, 2006. 
Redes de aprendizagem: boas práticas de municípios que garantem o direito de aprender. Brasília: Ministério da Educação, 2008.

OLIVEIRA, A.P.M. A Prova Brasil Como Política de Regulação da Rede Pública do Distrito Federal, 2011. Disponível em: <http://repositorio.unb.br/bitstream/10482/9334/1/2011 AnaPauladeMatosOliveira.pdf>. Acesso em 10 set. 2013.

OLIVEIRA, R. Da universalização do ensino fundamental ao desafio da qualidade: uma análise histórica. Educação e Sociedade, v. 28, n. 100 - Especial, p. 661-690, 2007.

OLIVEIRA, R.P.; ARAUJO, G.C. Qualidade do ensino: uma nova dimensão da luta pelo direito à educação. Revista Brasileira de Educação, n. 28, 2005.

ORAIR, R. et al. Uma metodologia de construção de series de alta frequência das finanças municipais no Brasil com aplicação para IPTU e o ISS: 2004-2010. Pesquisa e Planejamento Econômico, v. 41, n. 3, 2011

ORGANIZAÇÃO DAS NAÇÓES UNIDAS PARA A EDUCAÇÃO, CIÊNCIA E CULTURA - UNESCO. O perfil dos professores brasileiros: o que fazem, o que pensam, o que almejam. Pesquisa Nacional Unesco. São Paulo: Moderna, 2004.

PARO, V.H. Progressão continuada, supervisão escolar e avaliação externa: implicaçóes para a qualidade do ensino. Revista Brasileira de Educação, v. 16, n. 48, 2011.

PINTO, J.M.R. Novas fontes de financiamento e o custo aluno-qualidade (CAQ). In: Justiça pela qualidade na educação. ABMP, todos pela educação (Org). São Paulo: Saraiva, 2013. p. 288-311.

PIRES, D.B. Disciplina: construção da disciplina consciente e interativa em sala de aula e na escola. Educação \& Sociedade, v. 20, n. 66, 1999.

RAMAGE, W.R.; HOWLEY, A. Children's experiences of long bus rides: Parent's perspectives. American educational research association, Chigaco, 2003.

RESENDE, M.; WYLLIE, R. Retornos para educação no Brasil: evidências empíricas adicionais. Economia Aplicada, v. 10, n. 3, p. 349-365, 2006.

SACAVINO, S. Direito humano à educação no Brasil: fundamentos teórico-metodológicos. In: Encontro Nacional de didática e Prática de Ensino, 13, 23 a 26 abril, Recife, 2006, p. 23-26, Anais... Recife: UFPE, 2006.

SALGADO JUNIOR, A.P.; NOVI, J.C. Proposta de práticas administrativo-pedagógicas que possam contribuir para o desempenho dos alunos de escolas municipais do ensino fundamental na Prova Brasil. Ensaio (Fundação Cesgranrio. Impresso), v. 23, n. 88, p. 631-662, 2015.

Proposta metodológica: avaliação externa e desempenho dos alunos. Revista Brasileira de Política e Administração da Educação, v. 30, n. 3, 2014.

SALGADO JUNIOR, A.P.; NOVI, J.C.; FERREIRA, J.; OLIVEIRA, M.M.B.; MIRANDA, P.S. Eficiência na Gestão Escolar: em busca das melhores práticas em escolas municipais brasileiras do ensino fundamental. Meta: Avaliação, v. 7, n. 19, p. 85-122, 2015.

SARAFIDIS, V. An Assessment of Comparative Efficiency Measurement Techniques. London: European Economics, 2002. 
SAVIAN, M.; BEZERRA, F.; MELO, C. Análise de Eficiência dos Gastos Públicos com Educação no Ensino Fundamental nos Municípios do Estado do Paraná Evidências para os anos de 2005 e 2009. In: X ENABER, 2012, Recife. X ENABER, 2012.

SETÚBAL, M.A. Equidade e Desempenho Escolar É possível alcançar uma educação de qualidade para todos. Revista Brasileira de Estudos Pedagógicos, v. 91, n. 228, p. 345-366, 2010.

SMITH, J.P.; NAYLOR, R.A. Determinants of Degree Performance. University of Warwick. Oxford Bulletin of Economics and Statistics, v. 63, p. 29-60, 2001.

SOARES, J.F.; ALVES, M.T.G.; OLIVEIRA, R.M. O efeito de 248 escolas de nível médio no vestibular da UFMG nos anos de 1998, 1999 e 2000. Estudos em Avaliação Educacional, n. 24, p. 69-117, 2001.

SOARES, J.F.; XAVIER, F.P. Pressupostos educacionais e estatísticos do Ideb. Educação \& Sociedade, v. 34, n. 124, p. 903-923, 2013.

SOUZA, L.V.A. de; SOUZA, I.M.A. de; BONFIM, E.C. Leitura no ambiente escolar: do incentivo à prática. In: Colóquio Internacional Educação e Contemporaneidade, 4., 22 a 24 set., 2010. Anais... São Cristóvão: NPGED, 2010.

TEIXEIRA, R.A. Espaços, recursos escolares e habilidades de leitura de estudantes da rede pública municipal do Rio de Janeiro: estudo exploratório. Revista Brasileira de Educação, v. 14, n. 41, p. 232-390, 2009.

VASCONCELOS, C. dos S. Disciplina: construção da disciplina consciente e interativa em sala de aula e na escola. São Paulo: Libertad, 1995.

VELOSO, F. A evolução recente e proposta para a melhoria da educação no Brasil. In: BACHA, E.; SCHWARTZMAN, S. (Orgs.), Brasil: A Nova Agenda Social. Rio de Janeiro, LTC, p. 215-253, 2011.

VERGARA, S.C. Gestão de pessoas. 4a ed. São Paulo: Atlas, 2005.

ZOGHBI, A.C.P.; MATTOS, E.H.C. de; ROCHA, F.F.; ARVATE, P.R. Mensurando o desempenho e a eficiência dos gastos estaduais em educação fundamental e média. Estudos Econômicos, v. 39, n. 4, p. 785-809, 2009.

Recebido em 20 de janeiro de 2014.

Aceito em 29 de janeiro de 2016. 